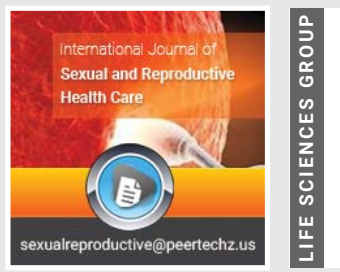

\title{
Pregnancy and childbearing among Adolescents and Young Persons Living with HIV: The Case of Chitungwiza, Harare
}

Received: 15 July, 2021

Accepted: 29 July, 2021

Published: 30 July, 2021

*Corresponding author: Norman Makunika, Student, Department of Demography, Chulalongkorn University, Thailand, Tel: +263776756270; E-mail:nmakunika@gmail.com ORCID: https://orcid.org/0000-0003-0129-4445 https://www.peertechzpublications.com

Check for updates

\author{
Norman Makunika1* and Lianora Manyange ${ }^{2}$ \\ 'Student, Department of Demography, Chulalongkorn University, Thailand \\ 2University of Zimbabwe, Center for Population Studies, Zimbabwe
}

\begin{abstract}
It is almost four decade into the HIV pandemic, the outlook of the disease has advanced significantly from death sentence to a chronically manageable disease that can be lived with for long time. This evolution was made possible with the advent of antiretroviral therapy which allowed HIV infected children to reach adulthood. However, sexual, and reproductive needs of these generations remain unattended in many countries. The study sought to highlight the sexual and reproductive health issues affecting young people living with HIV in Chitungwiza and Waterfalls communities, targeting HIV positive young people aged 15-24 years. A mixed methods approach was adopted in which, Qualitative and Quantitative research methods were employed. A survey was conducted with 113 young people to quantify sexual and reproductive health issues affecting young people living with HIV (YPLWH). To solicitate community perceptions and opinions on childbearing among the Adolescents and Young persons living with HIV, 8 focus group discussions and key informant interviews were conducted to qualify the data from the survey. The findings indicated that sexual and reproductive health (SRH) knowledge heavily impacts YPLWH' decision to have children. The sources of information may also affect decisions made by YPLWH. Socio-cultural barriers are major inhibiting factors limiting YPLWH and it was also observed that sero-status disclosure has direct impact on decision for condom use. The study recommends that academic research, NGOs, and other stakeholders with support from the Ministry of Health, should conduct more studies on emerging HIV and SRH issues which will help in addressing knowledge gaps and provide evidence-based knowledge in public health. Overall, this will improve the reproductive health outcomes of young people living with HIV.
\end{abstract}

\section{Introduction}

HIV infection reached unprecedented levels among heterosexual populations. Consequently, there were also birth of HIV infected children some of whom are currently in their sexually active ages. Zimbabwe National Adolescent and Youth Sexual and Reproductive Health Strategy (2016-2020) highlighted that the provision of sexual and reproductive health services, including education was consistently concentrated on adults and high-risk groups leaving out the entire population including young people. This exclusion of young people in SRH issues is a problem among adolescents and young people in general, and a double jeopardy to YPLWH. As a result, young people living with HIV persistently face challenges in managing sexual relationships, safer sexual behaviour, access and utilisation of contraceptives and decisions on childbearing. Thus this research seeks to investigate Sexual and reproductive issues that pertains to pregnancy and child bearing among adolescents living with HIV.

HIV infection reached unprecedented levels among heterosexual populations. Consequently, there were also birth of HIV infected children some of whom are currently in their sexually active ages. Zimbabwe National Adolescent and Youth Sexual and Reproductive Health Strategy (2016-2020) highlighted that the provision of sexual and reproductive health services, including education was consistently concentrated on adults and high-risk groups leaving out the entire population including young people. This exclusion of young people in SRH issues is a problem among adolescents and young people in general, and a double jeopardy to YPLWH. As a result, young people living with HIV persistently face challenges in managing sexual relationships, safer sexual behaviour, access and utilisation of contraceptives and decisions on childbearing. 
Thus, this research seeks to investigate the sexual and reproductive health issues affecting young people living with HIV pertaining to pregnancy and childbearing.

\section{Research objectives}

The overall objective of this study is to highlight the sexual and reproductive health issues affecting young people living with HIV pertaining to childbearing and pregnancy.

\section{Specific objectives}

1. Examine the salient sexual and reproductive health challenges faced by young people living with HIV pertaining to pregnancy and childbearing.

2. Describe the behavior and practices of young people living with HIV pertaining to pregnancy and childbearing.

\section{Methodology and study design}

The study was carried out in Waterfalls and St Mary's districts of Chitungwiza in Harare Province. Currently, Chitungwiza is one of the suburbs with a high HIV prevalence of $8.4 \%$ whereas Waterfalls constitute a moderately low 13.3\% (Global Aids Response Progress Report 2017). Waterfalls is a medium density suburb while St Mary's is a high-density residential community. These two areas were selected because they are urban areas with YPLWH from low income and middleincome backgrounds.

\section{Target population}

The target population was young people living with HIV aged between 15-24 years. Fifteen years was set as minimum age because young people become sexually active around age fifteen. The maximum age was set at 24 years because the maximum age for one to qualify to be a young adult is 24 year (WHO, 2015; UNFPA, 2004:2016).

\section{Study design}

The study triangulated qualitative and quantitative research methods. Focus group discussions (FGDs), key informant interviews (KIIs) and in-depth interviews were used to gather qualitative data. A survey was carried out so as to collect quantitative data. Qualitative data was analyzed using thematic analysis, whilst quantitative data was analyzed using descriptive statistics. The respective methods are discussed in detail below.

\section{Data collection methods and tools}

Survey : A survey was carried out using a questionnaire. The questionnaire was designed drawing from the most outstanding issues defined in FGDs. A survey was carried out so as to quantify the salient sexual and reproductive health issues faced by young people living with HIV. A survey also quantified the accessibility, affordability and utilization of SRH services in St Mary's and Waterfalls by YPLWH respectively. prevalence of $6 \%$ (ZNAC, 2015) against a national prevalence of

\section{Sample size determination}

The sample size (n) was calculated using the formula:

$\mathrm{n}=\left(\mathrm{Z}^{2} \mathrm{pq}\right) / \mathrm{e}^{2}$

$\mathrm{n}=$ the desired sample size;

$\mathrm{Z}^{2}=$ standard error set at (1.96) which normally corresponds to $95 \%$ confidence interval;

$\mathrm{p}=$ proportion of YPLWH (15 to 24 years) to the population in the two suburbs;

$\mathrm{q}=$ the proportion of total population of young people who are not HIV positive in both suburbs.

$\mathrm{e}^{2}=$ sampling error set at $(0.0495)$

The calculated sample size was 113 respondents.

\section{Sampling frame}

The sampling frame was composed of four health centers working directly with SOS Children's Villages in St Mary's (3) and Waterfalls (1). Thus, the sampling frame comprised a list of Waterfalls and St Mary's Clinic registers for YPLWHIV. YPLWH aged between $15-24$ years with at least 6 months of stay in the two communities were primarily targeted. Hence, the researcher had to randomly select the participants from the list.

\section{Sampling procedure}

The sampling design constituted four stages. Health centers were purposively selected targeting the four centers which are supported by SoS Children's Villages. There are three healthcare centers in St Mary's and one Waterfalls which work in partnership with SoS Children's Villages Zimbabwe in administering ARVs and delivery of SRH services for young people (FSP Manual; 2017). Thus, the clinics were purposively selected. The second stage involved getting client registers for YPLWH aged between 15 and 24 years. Each name on the register list was assigned a number and randomly selected. In order to ensure representation of respondents, probability proportional to size (PPS) sampling was applied. Respondents selected per center are shown in Table 1.

\section{Training of enumerators and pretesting}

A training session with four enumerators was done. The training focused on the purpose of the study, methodology,

Table 1: Distribution of YPLWH in St Mary's and Waterfalls per Age Group and per Healthcare Center.

\begin{tabular}{|c|c|c|c|c|c|}
\hline \multirow[t]{2}{*}{ Age Group } & \multicolumn{4}{|c|}{$\begin{array}{l}\text { Population of YPLWH Per Health Care } \\
\text { Center }\end{array}$} & \multirow[b]{2}{*}{ Total } \\
\hline & 1 & 2 & 3 & 4 & \\
\hline $15-17$ & 60 & 100 & 41 & 51 & 252 \\
\hline $18-20$ & 16 & 22 & 56 & 27 & 121 \\
\hline $21-24$ & 59 & 82 & 112 & 127 & 380 \\
\hline Total Population of YPLWH & 135 & 204 & 209 & 205 & 753 \\
\hline Sample per Healthcare Center & 20 & 31 & 31 & 31 & 113 \\
\hline & & & & & 068 \\
\hline
\end{tabular}

Citation: Makunika N, Manyange L (2021) Pregnancy and childbearing among Adolescents and Young Persons Living with HIV: The Case of Chitungwiza, Harare. Int J Sex Reprod Health Care 4(1): 067-072. DOI: https://dx.doi.org/10.17352/ijsrhc.000026 
clarity and familiarization with the questionnaire. During the training, clarification of every question and optional responses was done. This was important to ensure consistency in data collection. After the training session, the research instrument was pre-tested in St Mary's Ward 5, a ward which has similar socio-economic characteristics with wards that were targeted for the study. Finally, a debriefing meeting highlighting errors in the questionnaire was held. Respective questions were corrected and finalized.

\section{Focus Group Discussions (FGDs)}

The study conducted 8 FGDs, with 10 young persons each using a focus group discussion guide. FGDs were conducted with YPLWH aged between 15 and 24 years. Factors of homogeneity and heterogeneity were considered during the process of selecting participants. Participants were selected basing on the following age cohorts 15-17 years, 18-20 years, 21-24 years in Waterfalls and Chitungwiza respectively. In each age group respondents who were not involved in the survey were selected. FGDs were undertaken so as to examine group generated attitudes about the salient sexual reproductive health issues faced by YPLWH in St Mary's and Waterfalls. FGDs were also undertaken so as to assess group generated perceptions about the accessibility, affordability and utilization of SRH services by YPLWH. Purposive Snowballing sampling was used to select the FGDs participants so as to eliminate wrong targeting and minimize bias. All the FGDs in St Mary's were carried out at St Mary's Community Hall close to St Mary's Clinic where YPLWH usually come for their support groups and collection of antiretroviral drugs (ARVs). A facilitator who is the author of this research facilitated each FGD discussion in the vernacular language, while a trained research assistant took notes. The discussions were also tape recorded.

\section{Key informant interviews}

Eight face to face key-informant interviews using a key informant guide were conducted. They were carried out with two key informants from each of the following categories: Community Adolescents Treatment Supporter (CATs), Nurses, SOS Children's Villages Zimbabwe and Doctors operating in St Mary's Chitungwiza and Waterfalls. Heads in the respective groups were selected based on their experience and knowledge in SRH and HIV programming particularly dealing with adolescents and young people. Therefore, in-depth interviews with these stakeholders were done using a key informant guide to obtain their views on major SRH issues affecting young people living with HIV. In addition, KIIs provide important recommendations of the study. The data from KIIs was collected through note taking and audio recording.

\section{Data management and analysis}

The questionnaires used to conduct the survey were given codes before data collection. All the quantitative data collected was entered, cleaned, and analyzed using Statistical Package for Social Sciences (SPSS). A univariate analysis was used to quantify YPLWH's awareness and attitudes. Cross -tabulations were used to test basic relationship and a chi-square test was used to evaluate the strength of relationships between the variables. The $\mathrm{p}$-value of $<0.05$ was considered as statistically significant. Qualitative data was captured through note-taking and audio recording. The data was numbered, transcribed, coded and analyzed using thematic analysis. During the process of thematic analysis, six steps were undertaken. Firstly, familiarization with the data was done through listening to recordings and re-reading the transcripts. The second procedure involved generation of initial codes. The third step involved the selection of themes and sub-themes. The fifth stage involved the defining and naming of potential sub-themes. Finally, the sixth step involved generating a report relating to the research question. However, data were reported in a used complementary fashion.

\section{Ethical considerations}

The following offices namely; University of Zimbabwe' Ethical Committes, District Administrator (DA) of Waterfallsas well as DA Chitungwiza approved the study to be carried out. The Study was submitted and approved my the Medical Research Council of Zimbabwe, and Ethical clearance was sought.

In order to get informed consent from the participants, the researcher explained the purpose of the study to the respondents. Potential risks and benefits of the study were also explained in vernacular Shona language. Participants were told that the benefits of the study were indirect since the study was intended to inform program designing, policy making or policy review. Again, such information would then be used as evidence-based data to assist the improvement of reproductive health delivery for YPLWH. Anonymity was ensured using coded questionnaires without names. The researcher also explained to the participants that the information obtained from the study was going to be kept confidentially by placing protected passwords on software data, while hardware data was going to be kept in lockable metal filing cabinets. After this, participants voluntarily agreed to take part in the study. At the end of the discussions, respondents were asked if they had any pertinent questions. Each responded signed a consent form before responding to the interviews.

\section{Research findings}

In order to assess the prevalence of pregnancy among YPLWH, sexually active participants were asked whether they had ever pregnancy/impregnate someone. The analysis shows that $33 \%$ had experienced pregnancy while the majority, $67 \%$, never had pregnancy experience (Table 2). Qualitative data revealed that young people living with HIV did not want pregnancy because they believe that they may die before they raise their children. A common theme was noted in the qualitative data that young people would want to avoid pregnancy because it brings emotional and physical burden to the already burdened person. A young woman aged 21 during an in-depth interview gave the following remark:

"Pregnancy not good to my health, especially when the man does not want to take responsibility or if the family is not accepting it."

Citation: Makunika N, Manyange L (2021) Pregnancy and childbearing among Adolescents and Young Persons Living with HIV: The Case of Chitungwiza, Harare. Int J Sex Reprod Health Care 4(1): 067-072. DOI: https://dx.doi.org/10.17352/ijsrhc.000026 
Table 2: Percentage response of young people's intentions on having children in future.

\begin{tabular}{|c|c|c|}
\hline \multicolumn{3}{|c|}{ Intentions to have children } \\
\hline Variable $(n=113)$ & Percentage & P-value \\
\hline \multicolumn{3}{|c|}{ Age (years) } \\
\hline $15-17$ & 47.2 & \multirow{3}{*}{0.004} \\
\hline $18-20$ & 68.1 & \\
\hline $21-24$ & 74.9 & \\
\hline \multicolumn{3}{|c|}{ Sex of Respondents } \\
\hline Male & 49.2 & \multirow{2}{*}{0.013} \\
\hline Female & 68.4 & \\
\hline \multicolumn{3}{|c|}{ Marital Status (n=113) } \\
\hline Married/Cohabiting & 66.5 & \multirow{4}{*}{0.001} \\
\hline Never Married & 55.3 & \\
\hline Widowed & 30.7 & \\
\hline Divorced & 21.2 & \\
\hline \multicolumn{3}{|c|}{ Parity $(n=113)$} \\
\hline 1 & 62.3 & \multirow{5}{*}{0.011} \\
\hline 2 & 30.0 & \\
\hline 3 & 23.5 & \\
\hline 4 & 13.6 & \\
\hline $5+$ & 71.3 & \\
\hline \multicolumn{3}{|c|}{ Level of education } \\
\hline None & 62.1 & \multirow{5}{*}{0.083 (NS) } \\
\hline Primary Education & 55.2 & \\
\hline Secondary Education & 53.1 & \\
\hline High School Education & 50.1 & \\
\hline Tertiary & 45.6 & \\
\hline \multicolumn{3}{|c|}{ Level of income } \\
\hline Less than $\$ 100$ & 55.9 & \multirow{4}{*}{0.072 (NS) } \\
\hline$\$ 101$ to 250 & 53.2 & \\
\hline$\$ 251$ to $\$ 500$ & 44.9 & \\
\hline Above $\$ 500$ & 43.9 & \\
\hline Total & 69.1 & \\
\hline
\end{tabular}

Although, very few participants reported ever had pregnancy, the study assessed the intentions of young people to have children in future. Participants were asked whether they have intentions to be pregnant in future or not. The analysis observed an intricate relationship between age $(\mathrm{p}=0.004)$, sex $(p=0.013)$, marital status $(p=0.001)$ and parity $(0.011)$. Although intentions to have children was reported across all age groups, analysis observed that as age increase, the desire to have children also increase. For instance, $75 \%$ of young people aged 21-24 years had intentions to have children in future, $68 \%$ in age group 18-20 years indicated the same. However, the intentions reduced to less than half, $47 \%$ among age group 15-17 years. Qualitative findings observed that young people aged between 15-17 years are more likely to be in secondary school and hence their future will be focused much on pursuing education than having children. Note the following remark from one of the young man aged 17 years:

"My education comes first, l cannot be an HIV positive person with no education, my sister life will be hard l better play my cards smart and pursue my education. That wayl may have a good life and marry a good wife" (Male participant, Male FGD Waterfalls).

A young girl aged 16 years also echoed similar perception in her remarks during an in-depth interview:

"Being positive with no education is just makes life so miserable because you cannot depend on parents for the rest of your life, education is my priority for a me to live the kind of life that l desire." (Female participant, Waterfalls).

It is interesting to note that women had intention to have children in future than men. While $68 \%$ of young women reported having intentions to have children in future, less than half, $49 \%$ of male respondents reports the same. It was revealed during the FGDs that young men were afraid of failing to provide for the children. In women's groups there were perceptions that children are the once who makes women stay in a marriage and keeps your man closer to you. They perceive that if one gets married and takes time to have children the man might lose interest and find another woman. One young lady expressed her opinion during an FGD and others supported:

"Marriage without children is just a living arrangement, when you have children for your husband you become part of the family and even your in-laws will respect you" (Female participant, 21; FGD Chitungwiza).

One young man during an in-dept interview expressed the following remark with tears in his eyes:

"It is a dream of every man to marry, have children and live happily. Sadly, HIV positive men cannot even afford to cloth ourselves what more now when l have a family" (Male participant; Waterfalls).

An intricate relationship was observed between marital status and intention to have children. For instance, while $67 \%$, respondents who were married had intentions to have children, only $14 \%$ of those widowed reported the same. Findings from the qualitative data revealed that young people who were widowed were traumatized and with life experience and they no longer have hope to have children in future. One young lady widow at the age of 20 gave the following remark during an in-depth interview:

"I helplessly watched my child dying in my hands at the age of 17 , after 2 years in marriage, barely 3 months after the death of my child my husband died. I don't think 1 would want to have another experience of witnessing the death of my own child like that again in my life" (Female respondent, Chitungwiza).

\section{Discussion of findings}

The study observed that becoming pregnant outside marriage is a big problem for African girls than in developed countries. For instance, 37\% reported that they may decide to terminate unintended pregnancy. Although studies by Macintyre, et al. (2010) in North America reported that above $60 \%$ of pregnant HIV positive young women are not married, the American Institute of Health reported that more than half terminated the pregnancy. However, in a study conducted in Tanzani by Sosley (2013) on experience of HIV positive single women, about $22 \%$ of women commit unsafe abortion. An article published by Chronicles (2017) as quoted in [1] revealed that cases of unsafe abortion increased by $6 \%$ in 2016 and in an interview with a representative from National Family Planning Council, it was observed that perceived social and economic challenges are factors leading to unsafe abortion. 
All women including women living with HIV should have support for them to achieve their reproductive goals in safest possible manner. Young women with HIV have high intentions of childbearing, as such non-stigma information sharing, and support should reach to young women. The study findings revealed that $69 \%$ of HIV positive women had intentions of childbearing. However, the intentions varied by age, parity, marital status and sex. Studies conducted in Malawi by UNAIDS [2] on behavioural and social experience for adolescents with HIV reported similar finding, where $61 \%$ of young women with HIV (18-24 years) reported that they were intending to have children before the age of 30 . West Africa Journal of Medicine by Salami, et al. (2011) revealed that $68 \%$ of young women who have been on ART since birth have more intentions to have children compared to newly ART patients. Similar studies conducted in Zimbabwe at Wilkins hospital in Harare on sexual and reproductive health need for HIV positive teens observed that $58 \%$ of young people on ART desire to have children in future. This points to the need to incorporate pregnancy and childbearing education in HIV treatment especially for young women.

Fear to give birth to an HIV positive baby is common among women with HIV and there is need for health workers to provide adequate counselling to women who are planning to have children. Although $69 \%$ of HIV positive young women reported intentions to have children in this current study, $36 \%$ reported ever had pregnancy. The study also observed potential decisions on unwanted pregnancy, 37\% respondents reported that they may terminate the pregnancy. Frequently cited reason for terminating pregnancy was fear to give birth to an HIV positive child. Studies conducted in Botswana by UNICEF (2015) revealed that $34 \%$ of YPLWH gave birth to HIV positive babies and there is high unsafe abortion reported in this target group. Supporting studies conducted by Romez [3], Woog [3] and Mhloyi [3] in Zimbabwe, it was observed decision to commit abortion among young people is associated with fear to give birth to an HIV positive child. These results call for a need to educate HIV positive young women about pregnancy and childbearing.

Many studies have associated poverty with early and unwanted pregnancy. This study observed that low-income earners and those with no income were more likely to have early pregnancy compared to those with income above \$500. Studies conducted in Tanzania by Tesfaye (2017) observed that half of early pregnancy was found among the poorest women. Studies conducted in Nigeria, revealed that adolescents with poor parents were $60 \%$ more likely to engage in pre-marital sex than those whose parents were high income earners. In Zimbabwe, Mhloyi, et al. (2016) majority of young people involved in sexual relationship with older men who give them the " 3 Cs" i.e. cash, cell phones and car and given such benefits young women are not able to negotiate safe sex and thus end up pregnant. The inability of young women to meet their personal need expose them to unsafe sex and some end up in prostitution as a way of earning money [4].

Similarly, age and marital status were observed to be predictors of pregnancy among young women with HIV. The study observed that $67 \%$ married respondents have intentions to get pregnancy and $75 \%$ of women in age group 21-24 expressed intentions to have children. UNICEF report (2017) corroborate with these findings where concentration of pregnant women was among married women in age group 20-24 years. Obare, et al. [5] reported that in an African community marriage marks the beginning of childbearing for every woman. Studies conducted in Malawi and Zambia by UNFPA (2017) revealed that $60 \%$ of poor families force their young girls into marriage as early as 15 years. According to the Zimbabwe Demographic Health Survey community, mean age at first marriage is 18 years, hence young women experience family pressure to get married once they reach the age of 20 years. Generally married women do not experience unintended pregnancy than unmarried women. Since the study observed that majority, $41 \%$ YPLWH were not married hence the likelihood of unintended pregnancy can also be high. Also, in an African society it is more acceptable for married women to access SRH service. Therefore, unmarried young women are less likely to access SRH services. Thus, there is need to educate people on SRH so that YPLWH may have social support to utilize available SRH services [6-13].

\section{Conclusion and recommendations}

According to the findings of this study, places to get contraceptive has a bearing to access and utilization of contraceptives. Community health worker was the most cited convenient and preferred place for YPLWH to access contraceptives. In addition, YPLWH expressed the desire to have children but they fear to give birth to HIV positive children and there were socio-cultural factors which may influence them to commit unsafe abortion. Hence, there need for educative programs to increase SRH knowledge for young people living with HIV for them to make knowledgeable decision. It is also important for academia research findings to be disseminated to communities so as to demystify some perceptions and believes which may be proven wrong in public health. There is also need for Ministry of Health and Child Care (MoHCC) to improve service delivery system for it to be youth friendly and promote privacy and confidentiality. Unless the issue of knowledge, accessibility, and affordability of SRH services to YPLWH is not addressed, national efforts to achieve the positive sexual and reproductive health outcomes among adolescents and young people will continue to be a dream.

\section{Recommendations}

Consideration the study findings, the following are proposed recommendations to the improvement of programs and intervention which aim to address pregnancy and childbearing issues among young people living with HIV.

- MoHCC should continue to empower YPLWH for them to be able to disclose their status to their partners and also to ask their partners' status before sex.

There should be a continuum of care starting from the family, church and ending in public institutions. 
- Government should upgrade youth friendly corners and equip them with appropriate services needed by HIV positive young people.

- MoHCC should continue to capacitate health care workers on confidentiality so that young people may be able to privately access contraceptive and other SRH services.

\section{Declaration}

This articles was extracted from an original research that was conducted by the Author and is part of a larger research on Sexual and Reproductive Health Issues facing people living with HIV.

\section{References}

1. Mucheri T, Makunika N, Nyoni T, Mose N, Nhliziyo D, et al. (2021) Knowledge of HIV Prevention Methods among Adolescents. Journal of Medical and Dental Science Research 8: 72-80. Link: https://bit.ly/3lg4ROP

2. UNAIDS. Joint United Nations Programme on HIV/AIDS: UNAIDS DATA 2017 reference, 2018FHAPCO, GRHAPCO, UNAIDS. Synthesis of the HIV Epidemic and Response in Gambella. 2014

3. Remez L, Woog V, Mhloyi M (2016) Sexual and Reproductive Health Needs of Adolescents in Zimbabwe 21: 725-731. Link: https://bit.ly/2V4F69p

4. Makunika N, Manyange $L$ (2020) Determinants of HIV Prevention amongst Adolescents in Zimbabwe: The Case of Dzivarasekwa, Harare. International Journal of Sexual and Reproductive Health Care 3: 051-060. Link: https://bit.ly/3zON2uj
5. Obare F, Anke van der K, Adieri B, Owuor D, Okoth S, et al. (2010) HIV-positive adolescents in Kenya. Access to sexual and reproductive health services. Bulletin 393, Amsterdam, KIT Publishers. Link: https://bit.ly/3i8jv8R

6. Manyange L, Mucheri T, Nyoni T, Makunika N, Mose N (2021) Contraceptive use among Young Adults in Zimbabwe, Questionnaire Study. South Asian Journal of Social Studies and Economics 37-47. Link: https://bit.ly/3yhLIQf

7. Sosley L, Mhloyi M (1994) Fertility Levels and Trends in Zimbabwe. African E-journals.

8. Mhloyi M, Terry PE, Masvaure T, Adlis S (2006) An examination of knowledge, attitudes and practices related to HIV/AIDS prevention in Zimbabwean university students: Comparing intervention program participants and nonparticipants. Int J Infect Dis 10: 38-46. Link: https://bit.ly/3lce1vG

9. Tesfaye KR, Bibeau D, Steckler A, Glanz K (1988) An ecological perspective on health promotion programs. Health Educ Q 15: 351- 377. Link: https://bit.ly/3xekGbg

10. Macintrye H (2011) Beyond Sugar Daddies: Intergenerational sex and AIDS in urban Zimbabwe. AIDS and Behaviour 15: 1275-1282.

11. Sosley L, Mhloyi M (1994) Fertility Levels and Trends in Zimbabwe. African E-journals.

12. Moyo S, Rusinga O (2017) Contraceptives: Adolescents' Knowledge, Attitudes and Practices. A Case Study of Rural Mhondoro-Ngezi District, Zimbabwe. Afr J Reprod Health 21: 49-63. Link: https://bit.ly/376Qu7I

13. UNICEF, UNAIDS, PEPFAR (2006) Africa's orphaned and vulnerable generations: children affected by AIDS. Link: https://bit.ly/3rGfDiu

Discover a bigger Impact and Visibility of your article publication with Peertechz Publications

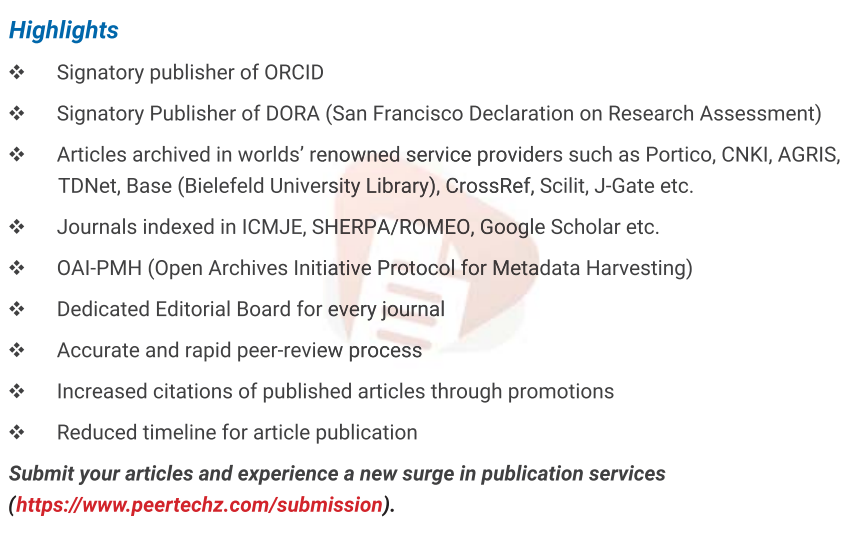

Peertechz journals wishes everlasting success in your every endeavours.

Copyright: ๑ 2021 Makunika N, et al. This is an open-access article distributed under the terms of the Creative Commons Attribution License, which permits unrestricted use, distribution, and reproduction in any medium, provided the original author and source are credited. 